\title{
Our Outcomes of Augmentation Mentoplasty with Solid Silicone
}

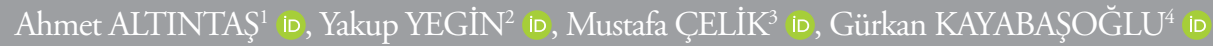 \\ ${ }^{1}$ Clinic of Otolaryngology-Head and Neck Surgery, Fatih Medicalpark Hospital, İstanbul, Turkey \\ ${ }^{2}$ Clinic of Otolaryngology-Head and Neck Surgery, Can Region Training and Research Hospital, Van, Turkey \\ ${ }^{3}$ Clinic of Clinic of Otolaryngology, Bakırkör Dr. Sadi Konuk Training and Research Hospital, İstanbul, Turkey \\ ${ }^{4}$ Department of Otolaryngology-Head and Neck Surgery, Sakarya University Training and Research Hospital, Sakarya, Turkey
}

\section{ABSTRACT}

Objective: To evaluate our outcomes of augmentation mentoplasty with solid silicone in patients with retrognathia.

Methods: In total, 17 patients (14 females, 3 males; average age 30.2 years; range 24-37 years) who underwent augmentation mentoplasty with solid silicone combined by septorhinoplasty were included in this study. Submental or gingivobuccal incision was performed in all the patients. The post-operative results of the augmentation mentoplasty were evaluated with reference to 3 criteria, i.e., patient satisfaction, physician aesthetic evaluation, and complications. The evaluation of the surgical results was formulated by adding scores from all 3 criteria.

Results: The mean follow-up was 18.5 months with the shortest and the longest being 4 and 33 months, respectively. Gingivolabial incision was performed in 4 patients $(23.5 \%)$ and submental incision was performed in 13 patients $(76.5 \%)$, respectively. There were no permanent complications in any patient. Overall, 15 patients $(88.2 \%)$ were extremely pleased with the procedure. In total, 16 patients $(94.12 \%)$ showed a significant improvement after augmentation mentoplasty with solid silicone according to the aesthetic evaluation by the physician. Revision mentoplasty was not performed in any patient.

Conclusion: Augmentation mentoplasty with solid silicone is a safe and effective means of creating a beautiful and balanced facial profile by producing alterations in the chin morphology with excellent and stable long-term results. Increased experience in augmentation mentoplasty will contribute to the further development of this surgery.

Keywords: Augmentation, mentoplasty, submental

\section{Introduction}

The facial aesthetics is formed by the symmetrical harmony of the facial skeleton and soft structures. The projection of the jaw also affects facial symmetry and harmony. The asymmetrical and disharmonious nature of the jaw disrupts facial aesthetics. In aesthetics, humans have always regarded the jaw as a symbol of courage and power $(1,2)$. Men with characteristic jaws have always been found to have stronger character and will $(2,3)$. There are a large number of studies on the size and position of the jaw. In fact, the size of the jaw is quite effective on the aesthetic appearance of the face, and it also affects the size of the face. Human jaw has different morphologies, such as vertical (micro or macrognathia), sagittal (retrognathia or prognathism), and transverse (symmetrical or asymmetric) planes (3-6). These different morphologies can sometimes be a presentation of craniofacial anomaly (7). Mentoplasty can be applied in two ways: osseous and alloplastic augmentation. Osseous mentoplasty is an important procedure that may lead to a sophisticated change in the jaw. Its advantages are facilitated by allowing a change in vertical, sagittal, and transverse planes, allowing the surgeon to shape the jaw to the desired shape and enabling the removal of a bone when required. It is a surgical procedure that is easy to implement and has good long-term results when performed by experienced surgeons (8-10). Today, most surgeons prefer augmentation mentoplasty owing to the easy and convenient delivery of the desired result. Contrary to popular belief, osseous

Cite this article as: Altıntaş A, Yegin Y, Çelik M, Kayabaşoğlu G. Our Outcomes of Augmentation Mentoplasty with Solid Silicone. Bezmialem Science 2018; 6: 21-6. 
mentoplasty is not a difficult operation, and furthermore, it provides a surgical success that cannot be achieved with augmentation mentoplasty when treating very short, very long, or asymmetric jaws. Mentoplasty is often a surgical procedure performed in addition to other facial plastic surgery procedures that are not performed alone $(11,12)$. Generally, in order to improve septorhinoplasty outcomes and increase patient satisfaction, mentoplasty is recommended by surgeons to patients who underwent septorhinoplasty operations (13).

In the present study, we evaluated the results of 17 patients who had undergone septorhinoplasty with augmentation mentoplasty. Patients were evaluated for septorhinoplasty operation.

\section{Methods}

This retrospective clinical study included patients who had applied to our hospital's otolaryngology-head and neck surgery outpatient clinic between December 2013 and May 2016, who were diagnosed with retrognathia as a result of facial and cephalometric analyses, and who underwent augmentation mentoplasty with septorhinoplasty operation. The study was conducted in accordance with the Guidelines for Good Clinical Practice and the principles of the Declaration of Helsinki. The ethics committee (decision no. 2017/04/02) of the same hospital approved the study. All the patients were informed about the study. Informed consent was obtained from the patients to participate in the study. There were a total of 17 patients, with 14 (82.4\%) female and 3 (17.6\%) male patients. The average age of the patients was 30.2 (range 24-37) years. In cephalometric analysis performed on all cases, the patients' mentocervical, nasomental, and Legan facial convexity angles were measured, and retrognathia diagnosis was made. Soft tissue analysis was performed on all cases. Both front and side profiles of all patients were evaluated. In the examination of the front profile, lip competence, facial height, and facial symmetry were evaluated. In the examination of the side profile, the labiomental fold (indentation between the lower lip and the lower portion of the mandible), the lip and chin relationship (the lower lip should ideally be 2-3 mm behind the upper lip), the cervicomental angle (angle between the jaw and the neck should be $105^{\circ}-120^{\circ}$ ), and the nose and chin relationship were evaluated. These two options were presented to the patients with no severe jaw deformity and whose deformities could be eliminated by augmentation mentoplasty or filling application without requiring horizontal osteotomy. Silicone implants (Eurosilicone, Z.I. de la Peyroliere, France) were used to provide mentum augmentation for patients who rejected volumetric synthetic filler (e.g., hyaluronic acid) and fat injection and who required a permanent solution. The average weight of the silicone implants used was 6-8 $\mathrm{g}$ with a dimension of $8 \times 65 \times 34 \mathrm{~mm}$. All cases were performed augmentation mentoplasty and gingivolabial or submental incision. For patients whose oral hygiene was not favorable and who rejected submental incision, gingivolabial incision was performed.
In addition to septorhinoplasty, all operations were performed under general anesthesia by the same surgeon. First, augmentation mentoplasty and then septorhinoplasty were performed. Before the injection of local anesthesia (1\% lidocaine+ $0.001 \%$ adrenaline), the labiomental sulcus, mental nerve, and submental folds were determined while the patient was in the supine position with head flexion. The submental incision was made with a $3 \mathrm{~cm}$ horizontal incision, parallel to the submental folds, from 3 to $4 \mathrm{~mm}$ below the submental line, from the midline along the sides. When in the subcutaneous skin, by bisecting the mentalis muscle, the mandibular periosteum was reached via a blunt dissection up to the upper edge of the lower mandibula. When the mandibular periosteum was reached, in order to minimize the risk of mandibular resorption, a surgical plan to provide subperiosteal in the midline and supraperiosteal in the laterals was presented. In this region, a pocket in which a silicone implant can be placed is formed. The silicone implant was rinsed with rifampicin ${ }^{\circledast}$ for prophylactic purposes and placed in this generated pocket. Then, it was fixed from the midline to the mandibula with a single screw. Bleeding control was performed, and the operation was terminated. The same surgical procedure was applied to selected cases with gingivolabial incision through the mouth (Figure 1. a-f).

Three criteria were used to assess surgical outcomes. These criteria are the following:

- Patient satisfaction assessment: patients were asked to rate their satisfaction with the surgical procedure performed in the third postoperative month

-1 , I am not satisfied;

-2 , I am satisfied;

-3 , I am very satisfied.

- Aesthetic evaluation by the physicians: all the cases were photographed 3 months before and after the operation and before and after photographs were compared (Figure 2. a-e). The photographs were evaluated by two physicians

-1, no significant improvement was observed;

-2 , there is significant improvement.

- Presence of postoperative complications: postoperative complications of the cases were evaluated as follows:

-1 , major complication; permanent loss of mental nerve sensory, presence of non-healing wounds, or necessity of a revision surgery;

-2 , moderate complication; loss of mental nerve sensory longer than a month, shorter than 6 months, and delay in wound healing;

-3, minor complication or no complication; loss of mental nerve sensory for less than a month or a complete recovery at the end of 1 month.

In the evaluation of the results, the sum of the scores of these three criteria was used. Results were as follows:

- excellent result: sum of scores 7 and 8,

- good result: sum of scores 5 and 6 ,

- poor result: sum of scores $<5$ (7). 
Table 1. General characteristics of the cases and outcome assessment

\begin{tabular}{|c|c|c|c|c|c|c|}
\hline \multirow{2}{*}{$\begin{array}{l}\text { Gender and age of the } \\
\text { patient }\end{array}$} & \multirow{2}{*}{$\begin{array}{l}\text { Type of } \\
\text { incision }\end{array}$} & \multirow[b]{2}{*}{ A } & \multicolumn{3}{|c|}{ Rating score } & \multirow[b]{2}{*}{ Outcome } \\
\hline & & & B & $\mathrm{C}$ & Total & \\
\hline $1-24$ years, female & SM & 3 & 2 & $3^{*}$ & 8 & Excellent \\
\hline $2-25$ years, female & $\mathrm{GL}$ & 3 & 2 & 3 & 8 & Excellent \\
\hline 3-25 years, female & $\mathrm{GL}$ & 3 & 2 & 3 & 8 & Excellent \\
\hline $4-26$ years, female & SM & 2 & 2 & $3 *$ & 7 & Excellent \\
\hline $5-27$ years, male & $G L$ & 2 & 1 & $3 *$ & 6 & Good \\
\hline $6-27$ years, female & SM & 3 & 2 & 3 & 7 & Excellent \\
\hline $7-28$ years, female & SM & 3 & 2 & 3 & 8 & Excellent \\
\hline $8-28$ years, female & SM & 3 & 2 & $3 *$ & 8 & Excellent \\
\hline 9-29 years, male & SM & 3 & 2 & 3 & 8 & Excellent \\
\hline $10-30$ years, female & SM & 3 & 2 & $3^{*}$ & 8 & Excellent \\
\hline $11-32$ years, male & SM & 3 & 2 & 3 & 8 & Excellent \\
\hline $12-33$ years, female & SM & 3 & 2 & 3 & 8 & Excellent \\
\hline $13-35$ years, female & $\mathrm{GL}$ & 3 & 2 & 3 & 8 & Excellent \\
\hline $14-35$ years, female & SM & 3 & 2 & 3 & 8 & Excellent \\
\hline $15-36$ years, female & SM & 3 & 2 & 3 & 8 & Excellent \\
\hline $16-37$ years, female & SM & 3 & 2 & 3 & 8 & Excellent \\
\hline $17-37$ years, female & SM & 3 & 2 & 3 & 8 & Excellent \\
\hline & $76.5 \%$ SM & & & & & $94.2 \%$ excellent \\
\hline & $23.5 \% \mathrm{GL}$ & & & & & $5.8 \%$ good \\
\hline
\end{tabular}

\section{Results}

The average follow-up period for all patients was 18.5 (range 4-33) months. Gingivolabial incision was performed on 4 (23.5\%) patients, and the remaining $13(76.5 \%)$ patients underwent submental incision. Of the patients who underwent submental incision, 5 (29.4\%) experienced transient paresthesia that lasted $<1$ month, whereas other cases experienced no complication. Of the cases, $15(88.2 \%)$ stated that the result of mentoplasty was excellent. In the aesthetic evaluation of the physicians, it was reported that $16(94.12 \%)$ patients had significant improvement. Table 1 shows the outcome assessment of the cases. None of the cases underwent revision mentoplasty.

\section{Discussion}

Despite the fact that the jaw has an important impact on facial shape and aesthetics, the shaping of the jaw was neglected in facial plastic surgery until 1940. For the first time in 1942, Hofer et al. (14) described anterior horizontal osteotomy on the distal jaw but did not share any visual content on their study. This did not facilitate understanding of the surgical procedure. In 1947, Gilles et al. (15) reported that they had performed mentoplasty on a patient with Treacher-Collins-
Franceschetti syndrome. In 1957, Trauner and Obwegeser (16) described the osseous mentoplasty technique through transoral approach to prevent incision scar line development in the submental region. Over time, the role of mentoplasty in facial aesthetics has been better understood, and mentoplasty has become a frequently used surgical procedure nowadays in facial plastic clinics. It is frequently used with other facial surgical procedures owing to many reasons, such as its easy application, low cost, and high patient satisfaction. Furthermore, it is becoming more and more important in facial feminization surgeries (17). The evaluation stage of the patients, the treatment plan, the surgical procedure to be performed, the possible complications, and the patient's followup are current issues for mentoplasty. Age, gender, race, cultural differences, and comorbid causes are factors in the decision of mentoplasty $(18,19)$. While women tend to have narrower and smaller jaw structure, men have the tendency to have rounder, wider, and square-shaped face structures. Similarly, age is an important factor for mentoplasty. Surgical intervention at an early age may reduce patient satisfaction in later periods due to the change of the facial skeleton with age. From another point of view, increased comorbidity and agerelated weakening of the jawbone structure that might be experienced at later ages will cause differences in the form of 
surgical interventions to be performed. For surgeries performed at later ages, augmentation mentoplasty should be preferred to osseous mentoplasty $(12,13)$. It should be noted that mentoplasty is an elective surgical procedure and should be applied on patients with hemodynamic stability considering comorbid factors. For instance, tobacco use, although it is not acknowledged as a contraindication for this procedure, should be taken into consideration since smoking increases complication risks, causes delays in wound healing, and reduces graft success if autograft is to be used $(7,15)$. In addition, for patients who will undergo mentoplasty, not only the lower part of the face but also the maxillofacial development, facial skeletal morphology, state of the teeth, and relation of the teeth to the jaw should be evaluated. The examination of dental morphology is very vital. Angle's classification can be

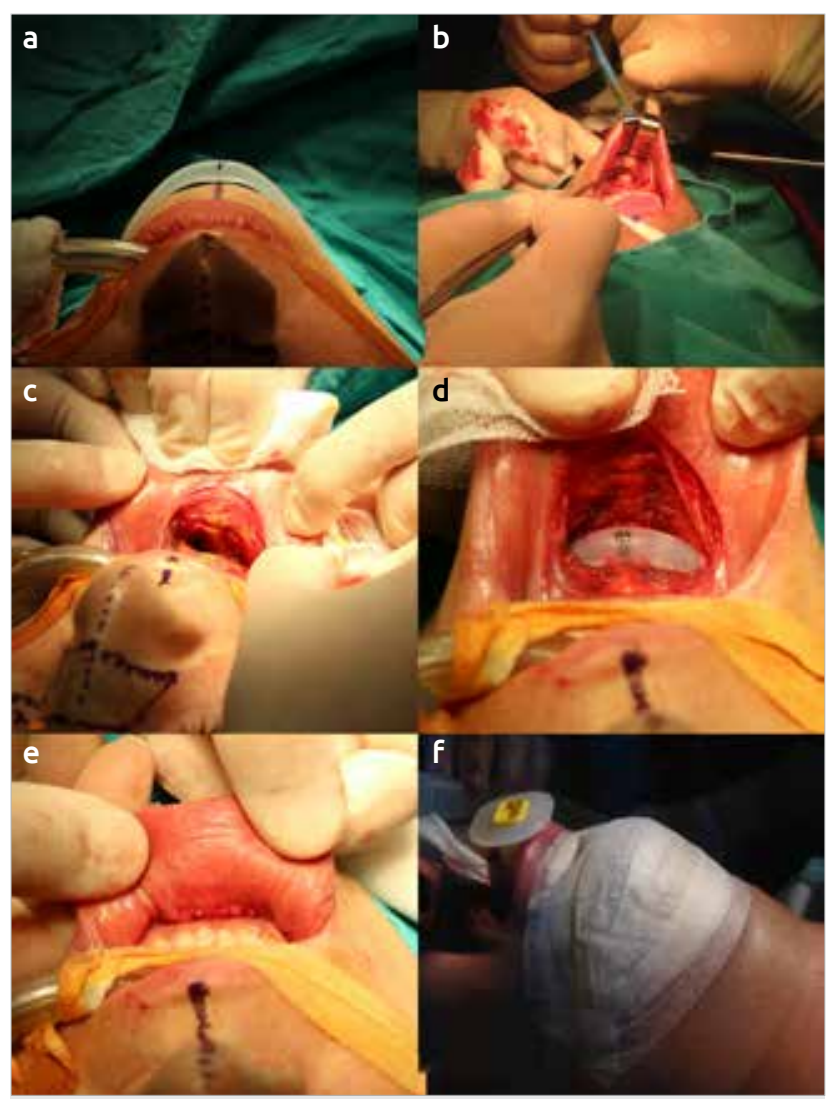

Figure 1. a-f. Surgical stages of gingivolabial incision and augmentation mentoplasty used to establish the relationship between maxilla and mandibula. Unhealthy or infected teeth should be treated prior to surgery. For facial skeleton interventions, cephalometric analysis is guiding, but for most patients, soft tissue and dental evaluation may suffice. Soft tissue analysis is important to determine the need for mentoplasty. Each patient should be examined both from the front and side profiles. For the front profile, lip competence, facial height, and facial symmetry should be examined. For patients with lip incompetence, osseous mentoplasty may be preferred. Face height should be checked to determine whether jaw enlargement or reduction is necessary and to understand the proportions. Face symmetry should be considered to determine if more than one osteotomy is required. In the examination of the side profile, the labiomental fold (indentation between the lower lip and the lower portion of the mandible), the lip and chin relationship (the lower lip should ideally be 2-3 $\mathrm{mm}$ behind the upper lip), the cervicomental angle (angle between the jaw and the neck should be $105^{\circ}-120^{\circ}$ ), and the nose and chin relationship are essential $(11,12)$. Finally, the lower face should be examined for skin type, and its quality, thickness, and elasticity should be determined. After collecting all the data required for surgery, optimal treatment should be planned. Patient's purposes and wishes should be taken into consideration, and questions of whether mentoplasty should solely be performed or whether it should be combined with treatments other than orthognathic surgery should be answered. In the majority of patients with septorhinoplasty, the anomaly in the jaw shape is either not considered or neglected. Simons et al. (20) reported that patients who underwent septorhinoplasty, although majority of them had retrognathia, were unaware of the situation unless they were told by the surgeon. The probable cause is that, although there are differences among societies, the mentoplasty process is not as common as septorhinoplasty or other aesthetic surgical procedures. Unless the patients' jaw deformities are very distinct, their unawareness can be attributed to their inadequate awareness. In these cases, patients should be informed about retruded jaw, about the success of septorhinoplasty, and that patient satisfaction may be reduced in case of jaw disharmony. Mentoplasty may not provide a significant increase in facial size but may lead to more satisfactory results in terms of septorhinoplasty. In general, for a defect that the patient is not aware of or is uncomfortable with, to propose surgery is neither economically nor ethically proper, except
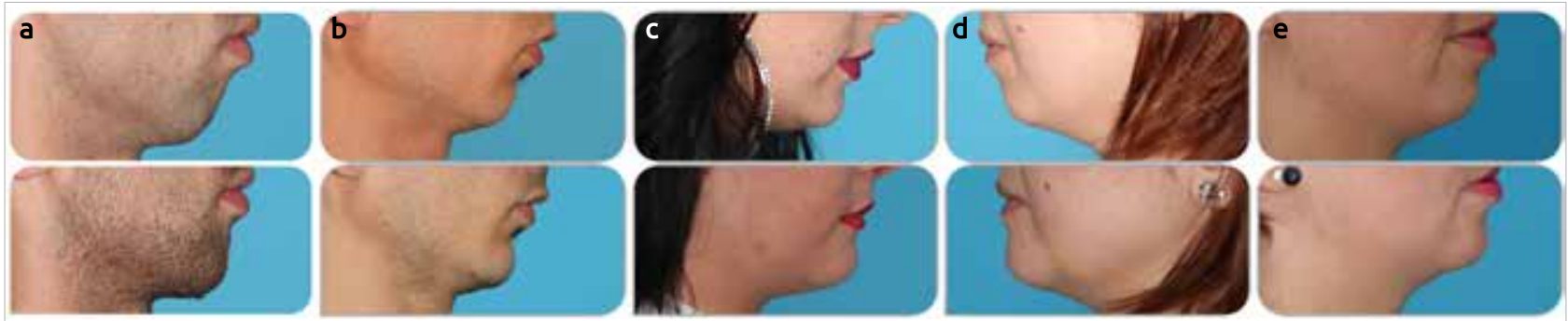

Figure 2. a-e. Preoperative (above) and postoperative (below) images of patients who were used in the aesthetic evaluation of the physicians 
for augmentation mentoplasty. In the present study, all of our cases were unaware that they had retrognathic jaws $(6,7)$. In the past, surgeons frequently preferred autograft materials. Recently, modern surgeons have been using autografts, such as costochondral grafts and bone grafts; however, these grafts have some disadvantages, such as resorption over time and development of deformity $(21,22)$. In the last two decades, alloplastic materials have been used owing to the advantages they provide, such as no donor morbidity, easy formability, placement in a very short time, and easy removal. Materials, such as Mersilene mesh, hydroxyapatite, porous polyethylene, polyamide mesh, acrylic, silastic, and polytetrafluoroethylene, with autografts obtained during septorhinoplasty, such as bone and cartilage humps, dental elements, dermal fat grafts, and conchal cartilage, can also be used (22-26). Nowadays, silicone implants are frequently preferred. In the present study, silicone implants were used in all cases. Silicone implants are important alloplastic materials that were started to be used in augmentation aesthetic surgery in the 1950s. Silicone implants are very durable, resistant to body heat, easily shaped, and resistant to impacts from the outside. Scaccia et al. (27) reported in a study that included $>10,000$ patients that the use of silicone implants is more reliable. They reported that silicone implants $(2.7 \%)$ are the materials with the least complication compared with Mersilene mesh, Proplast, and acrylic materials. In addition, Guyuron et al. (28) reported in a comparative study of osteoplastic and alloplastic augmentation mentoplasty that the use of alloplastic materials on cases with severe retrognathia, a high likelihood of symphyseal resorption, and distinct asymmetry on the vertical plane is not successful. However, it should be noted that alloplastic materials may cause foreign body reaction in the human body. In the present study, no foreign body reaction occurred in any of the cases, and no deformation was observed in the silicone implants during the follow-up period of the cases. Silicone placement with submental incision is more widely accepted. Since the implant placement performed through the transoral route causes irritation due to the sutures and more frequent infection development, the submental route is more commonly preferred. Despite the disadvantage of small scar development in patients undergoing submental incision, the incisions being made on the submental skin folds and a little further behind the jaw would reduce this scar development $(13,15)$. The most feared complications after implantation are mandibular resorption and defect development. Pearson et al. (23) reported that jaw implants cause resorption in the symphyseal area over time. Whether or not the implant material's supraperiosteal or supraperiosteal placement has an effect on the development of this defect has not yet been elucidated. Placement of the implant on the periosteum and continuation of blood flow of the mandibula through the periosteum will result in less mandibular resorption. At present, discussions are mostly about the placement of implants in very large dimensions. To our knowledge, there are no data in the literature on mandibular resorption in the use of small implants. Furthermore, mandibular symphyseal resorption development necessitates implant removal and revision surgery. In the present study, the implants were placed subperiosteally in the middle and subperiosteally in the laterals, and no permanent complication developed during the follow-up period of the cases.

\section{Conclusion}

We believe that augmentation mentoplasty should be applied in cases where it is deemed necessary because when applied with septorhinoplasty, it improves patient's satisfaction, and it is an easy surgical procedure. Augmentation is a reliable and effective surgery, leading to changes in jaw morphology and forming a balanced and beautiful face with excellent, stable, and long-term results. An increase in experience in this regard will contribute to further development and expansion of this surgery.

Ethics Committee Approval: Ethics committee approval was received for this study from the ethics committee of Bakırköy Dr. Sadi Konuk Training and Research Hospital (2017/04/02).

Peer-review: Externally peer-reviewed.

Author Contributions: Concept - A.A., Y.Y., M.Ç., G.K.; Design - A.A., Y.Y., M.Ç., G.K.; Supervision - A.A., Y.Y., M.Ç., G.K.; Resource - A.A., Y.Y., M.Ç., G.K.; Materials - A.A., Y.Y., M.Ç., G.K.; Data Collection and/or Processing - A.A., Y.Y., M.Ç., G.K.; Analysis and/or Interpretation - A.A., Y.Y., M.Ç., G.K.; Literature Search A.A., Y.Y., M.Ç., G.K.; Writing - A.A., Y.Y., M.Ç., G.K.; Critical Reviews - A.A., Y.Y., M.Ç., G.K.

Conflict of Interest: No conflict of interest was declared by the authors.

Financial Disclosure: The authors declared that this study has received no financial support.

\section{Reference}

1. Grammer K, Fink B, Møller AP, Thornhill R. Darwinian aesthetics: sexual selection and the biology of beauty. Biol Rev Camb Philos Soc 2003; 78: 385-407. [CrossRef]

2. Rhodes G, Yoshikawa S, Clark A, Lee K, McKay R, Akamatsu S. Attractiveness of facial averageness and symmetry in nonWestern cultures: in search of biologically based standards of beauty. Perception 2001; 30: 611-25. [CrossRef]

3. Rhodes G, Chan J, Zebrowitz L, Simmons LW. Does sexual dimorphism in human faces signal health? Proc Biol Sci 2003; 270: S93-5.

4. Frodel JL. Evaluation and treatment of deformities of the chin. Facial Plast Surg Clin North Am. 2005; 13: 73-84. [CrossRef]

5. Wolfe SA. Shortening and lenthening the chin. J Craniomaxillofac Surg 1987; 15: 223-30. [CrossRef]

6. Lee TS, Kim HY, Kim TH, Lee JH, Park S. Contouring of the lower face by a novel method of narrowing and lengthening genioplasty. Plast Reconstr Surg 2014; 133: 274e-82e.

7. Deshpande SN, Munoli AV. Osseous genioplasty: A case series. Indian J Plast Surg 2011; 44: 414-21. [CrossRef] 
8. Shaughnessy S, Mobarak KA, Høgevold HE, Espeland L. Long-term skeletal and soft-tissue responses after advancement genioplasty. Am J Orthod Dentofacial Orthop 2006; 130: 8-17. [CrossRef]

9. Miles BA, Leach JL Jr. Osseous genioplasty: Technical considerations. Oper Tech Otolaryngol Head Neck Surg 2007; 18: 181-8. [CrossRef]

10. Park JY, Kim SG, Baik SM, Kim SY. Comparison of genioplasty using Medpor and osteotomy. Oral Surg Oral Med Oral Pathol Oral Radiol Endod 2010; 109: e26-30.

11. Sykes JM. Orthognathic surgery. In: Papel I, editor. Facial plastic and reconstructive surgery. 3rd edition. New York: Thieme; 2009. p. 1095-118.

12. Nocini PF, Chiarini L, Bertossi D. Cosmetic procedures in orthognathic surgery. J Oral Maxillofac Surg 2011; 69: 716-23. [CrossRef]

13. Sykes JM, Suarez GA. Chin Advancement, Augmentation, and Reduction as Adjuncts to Rhinoplasty. Clin Plastic Surg 2016; 43: 295-306. [CrossRef]

14. Hofer D. Operation der Prognathie und Mikogenie. Dtsch Zahn Mund Kieferheilkd 1942; 9: 121.

15. Gilles HD, Millard DR Jr. The Principles and Art of Plastic Surgery, 1st ed. Boston, Mass: Little Brown and Co Inc; 1957.

16. Trauner $\mathrm{R}$, Obwegeser $\mathrm{H}$. The surgical correction of mandibular prognathism and retrognathia with consideration of genioplasty. I. Surgical procedures to correct mandibular prognathism and reshaping of the chin. Oral Surg Oral Med Oral Pathol 1957; 10: 677-89. [CrossRef]

17. Raffaini M, Magri AS, Agostini T. Full Facial feminization surgery: patient satisfaction assessment based on 180 procedures
Involving 33 consecutive patients. Plast Reconstr Surg 2016; 137: 438-48. [CrossRef]

18. Thayer ZM, Dobson SD. Geographic variation in chin shape challenges the universal facial attractiveness hypothesis. PLoS One 2013; 8: e60681.

19. Vuyk HD. Augmentation mentoplasty with solid silicone. Clin Otolaryngol Allied Sci 1996; 21: 106-18. [CrossRef]

20. Simons RL. Adjunctive measures in rhinoplasty. Otolaryngol Clin North Am 1975; 8: 717.

21. Godin M, Costa L, Romo T, Truswell W, Wang T, Williams E. Gore-Tex chin implants: A review of 324 cases. Arch Facial Plast Surg 2003; 5: 224-7. [CrossRef]

22. Beekhuis GJ. Augmentation mentoplasty with polyamide mesh. Update. Arch Otolaryngol 1984; 110: 364-7.

23. Pearson DC, Sherris DA. Resorption beneath silastic mandibular implants. Effects of placement and pressure. Arch Facial Plast Surg 1999; 1: 261-5. [CrossRef]

24. Bell WH, Gallagher DM. The versatility of genioplasty using a broad pedicle. J Oral Maxillofac Surg 1983; 41: 763-9. [CrossRef]

25. Adams JS. Grafts and implants in nasal and chin augmentation. Otolaryngol Clin North Am 1987; 20: 913-30.

26. Welling DB, Maves MD, Schuller DE, Bardach J. Irradiated homologous cartilage graft. Longterm results. Arch Otolaryngol Head Neck Surg 1988; 114: 291-5. [CrossRef]

27. Scaccia FJ, Allphina AL, Stepnick DW. Complications of augmentation mentoplasty: a review of 11095 cases. Int J of Aest Rest Surg 1983; 1: 3-8.

28. Guyuron B, Raszewski RL. A critical comparison of osteoplastic and alloplastic augmentation genioplasty. Aesthetic Plast Surg 1990; 14: 199-206. [CrossRef] 